\title{
Is topical haloperidol a useful glaucoma treatment?
}

\author{
MICHAEL J LAVIN' AND VICTOR ANDREWS ${ }^{2}$
}

From the 'Department of Ophthalmology, Western Ophthalmic Hospital, Marylebone Road, London NW1 $5 Y$ E, and the ${ }^{2}$ Department of Pharmacy, Moorfields Eye Hospital, City Road, London EC1V 2 PD.

SUMmARY A randomised, double blind, single dose study of topical haloperidol, a dopamine receptor blocking drug, was performed on 20 healthy volunteers. After its administration a modest reduction in intraocular pressure was recorded over the six-hour study period, but the difference was not significant at the $\mathrm{p}<0.05$ level. Although dopamine blocking agents are effective in reducing intraocular pressure in experimental animals, topical haloperidol appears unlikely to be clinically useful in the treatment of glaucoma.

We were stimulated to examine the effect of topical haloperidol, a dopamine receptor blocking drug, on human intraocular pressure (IOP) as a result of recent work regarding timolol's mechanism of action. Topical timolol is widely used in the treatment of glaucoma but is contraindicated in patients with cardiovascular or respiratory disease, as it may precipitate serious, occasionally fatal, side effects.' Timolol's major side effects are the result of beta adrenergic blockade. ${ }^{1}$ However, there is evidence that its inhibitory effect on aqueous humour secretion may not be a result of beta adrenergic blockade ${ }^{2-5}$ but of dopamine receptor blockade. .- $^{5-8}$

Timolol's action may not be mediated by beta receptors, since its binding to ocular beta receptors is short lived, though its ocular hypotensive action is long lasting. ${ }^{2}$ Natural beta receptors are orientated in favour of the L-isomer, so that D-timolol has only $3 \%$ of the systemic beta blocking action of L-timolol. However, D-timolol is as effective as the $\mathrm{L}$ isomer in reducing intraocular pressure (IOP) when infused into the cat eye. ${ }^{3}$ In addition timolol lowers intraocular pressure (IOP) in patients with third neuron Horner's syndrome, that is, in the absence of ocular sympathetic innervation. ${ }^{4}$

Timolol may act in part on dopamine receptors, since it reduces the concentration of dopamine in the iris and ciliary body but leaves adrenaline, noradrenaline, and prostaglandin levels unaffected. ${ }^{5}$

In animal experiments studying the recovery time of the IOP after intravenous infusion of hypertonic saline, topical dopamine increased the IOP while Correspondence to Mr M J Lavin, FRCS, Moorfields Eye Hospital, High Holborn, London WC1V 7AN. timolol reduced it. The effect of timolol was neutralised by simultaneous dopamine administration. ${ }^{6}$ In this experimental model topical haloperidol, a dopamine antagonist, reduces the IOP more profoundly and for a longer duration than timolol. ${ }^{78}$

Since there is a need for a long acting topical ocular hypotensive agent with no beta adrenergic blocking effects, we performed a single drop, double blind study of topical haloperidol in human volunteers.

\section{Subjects and methods}

This study was approved by the Ethics Committee of St Mary's Hospital. Twenty healthy subjects volunteered, and informed consent was obtained from all.

Sterile, viscous solutions of haloperidol $0.125 \%$ or haloperidol $1.0 \%$ in water containing $0.5 \%$ or $0.7 \%$ lactic acid respectively were prepared and found to have a pH 5.5.

Intraocular pressures were measured with a Goldmann applanation tonometer which was standardised before and after each test session. The same instrument was used throughout the study. The IOPs were measured after instilling topical benoxinate and fluorescein: 10 minutes before application of topical haloperidol and at two, four, and six hours after. Eye drops were instilled independently by trained ophthalmic nurses.

The first seven subjects received haloperidol $0 \cdot 125 \%$, while all others received haloperidol $1 \cdot 0 \%$. Saline or inert vehicle was applied to the control eyes. Test eyes were randomised, and the study was performed in a double blind fashion.

Visual acuities, brachial artery blood pressure, and 
Table 1 Mean percentage intraocular pressure differences from base line pressures

\begin{tabular}{|c|c|c|c|c|c|c|}
\hline \multirow[t]{2}{*}{ Preparation } & \multicolumn{2}{|c|}{$\%$ Difference at 2 hours } & \multicolumn{2}{|c|}{$\%$ Difference at 4 hours } & \multicolumn{2}{|c|}{$\%$ Difference at 6 hours } \\
\hline & Active & Placebo & Active & Placebo & Active & Placebo \\
\hline $\begin{array}{l}1 \% \text { Eye drops } \\
\text { (13 subjects) } \\
t \text { Test values for paired differences }\end{array}$ & $\begin{array}{c}-9.55 \\
( \pm 10 \cdot 01)\end{array}$ & $\begin{array}{l}-3 \cdot 55 \\
( \pm 8 \cdot 12)\end{array}$ & $\begin{array}{c}-9.84 \\
( \pm 13.08)\end{array}$ & $\begin{array}{c}-4 \cdot 99 \\
( \pm 10 \cdot 57)\end{array}$ & $\begin{array}{l}-6 \cdot 19 \\
( \pm 11 \cdot 77)\end{array}$ & $0.41^{-8 \cdot 06}( \pm 11 \cdot 44)$ \\
\hline $\begin{array}{l}0.125 \% \text { Eye drops } \\
\text { ( } 7 \text { subjects) } \\
t \text { Test values for paired differences }\end{array}$ & $\begin{array}{c}-15 \cdot 04 \\
( \pm 16 \cdot 53)\end{array}$ & $\begin{array}{l}-3 \cdot 73 \\
( \pm 11 \cdot 22)\end{array}$ & $\begin{array}{c}-1.93 \\
( \pm 10 \cdot 63)\end{array}$ & $2^{-5 \cdot 87}$ & $\begin{array}{l}-8 \cdot 1 \\
( \pm 14 \cdot 50)\end{array}$ & $1 \cdot 33^{( \pm 10 \cdot 90)}$ \\
\hline $\begin{array}{l}\text { Total mean \% differences } \\
\text { (20 subjects) }\end{array}$ & $\begin{array}{c}-11 \cdot 47 \\
( \pm 12 \cdot 52)\end{array}$ & $\begin{array}{r}-3.61 \\
( \pm 9.02\end{array}$ & $\begin{array}{l}-8 \cdot 26 \\
( \pm 12 \cdot 70)\end{array}$ & $\begin{array}{l}-5 \cdot 17 \\
( \pm 11 \cdot 70)\end{array}$ & $\begin{array}{l}-6 \cdot 72 \\
( \pm 12 \cdot 16)\end{array}$ & $\begin{array}{l}-5.07 \\
( \pm 12.04)\end{array}$ \\
\hline
\end{tabular}

Results given \pm one standard deviation. Results not significant at the $5 \%$ level $(t<1 \cdot 96)$.

pulse rate were measured at base line and at two and six hours after topical haloperidol. A full slit-lamp examination was performed before each IOP measurement, and subjects were questioned about ocular symptoms.

Volunteers were excluded from the study if there was any known or detected ocular disease, if any topical medication was in use, or if systemic beta adrenergic or dopamine receptor blocking agents were taken.

\section{Results}

Haloperidol produced a small reduction in IOP, with a maximum reduction of $11.4 \%$ at 2 hours. The mean reduction from baseline IOP in control eyes was $3.9 \%$ at 2 hours. Thereafter the difference between test and control eyes diminished (Fig. 1). The difference was not significant at $\mathrm{p}<0.05$ for the numbers tested. The ocular hypotensive effect of haloperidol was of small magnitude and short duration (Table 1).

Stinging was noted by all subjects and was of sufficient intensity to induce reflex lacrimation in most of them.

A fine punctate epithelial keratitis (PEK) developed in the lower half of both test and control eyes in $50 \%$ of subjects. ${ }^{10}$ The signs resolved within a few hours and were attributed to benoxinate induced epithelial toxicity.

However two of these 10 had PEK more marked on the test eye, and a further four subjects developed lower half PEK in the test eye only, with no signs on the control eye. Thus the haloperidol/lactic acid solution may have an element of acute epithelial toxicity which is mild and of short duration.

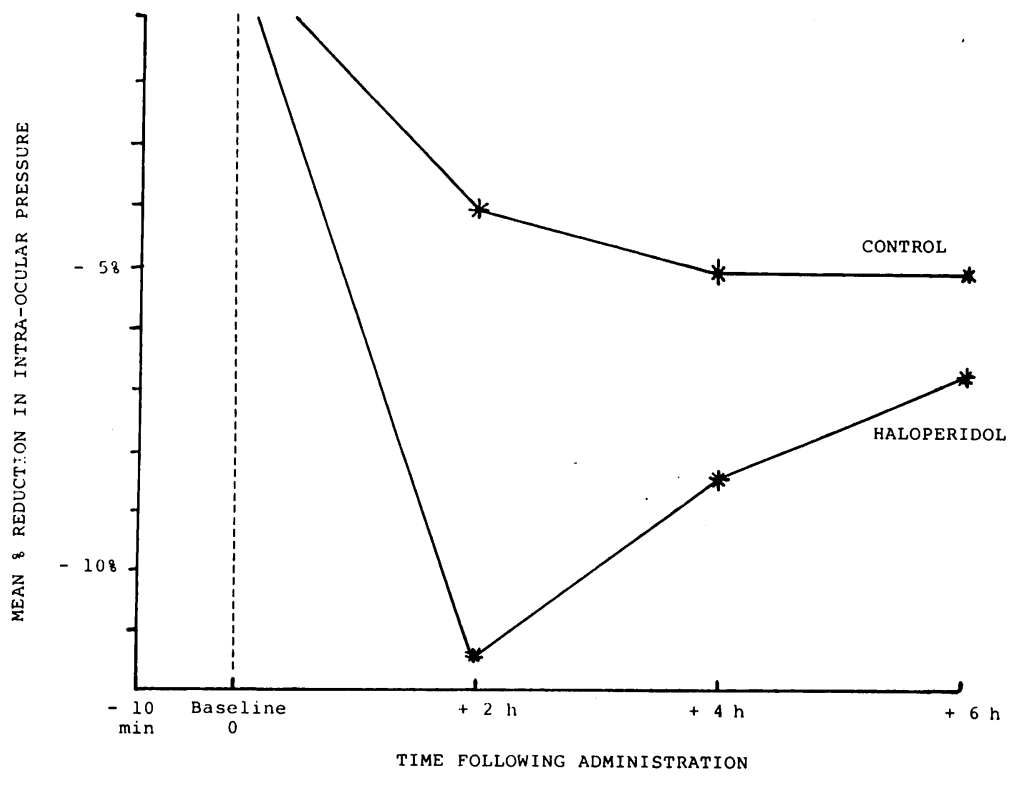

Fig. 1 Mean percentage reduction in IOP following topical haloperidol instillation. 
Pupil size, visual acuity, brachial artery blood pressure, and pulse rate were unchanged over the test period.

\section{Discussion}

We wished to answer the question of whether dopamine receptor blocking drugs are effective in reducing human intraocular pressure. We chose haloperidol because it is more effective in reducing cat IOP than other dopamine blocking drugs. ${ }^{8}$ In addition there is long clinical experience with the use of systemic haloperidol.

Studies in experimental animals have shown an impressive ocular hypotensive effect $(30 \%$ decrease in IOP) after topical haloperidol application, and it has been suggested that these drugs may be an effective treatment for glaucoma ${ }^{8}$ We believe that this is the first time topical haloperidol has been tested in humans. Our results show that haloperidol produces a small reduction in IOP at 2 hours which was not statistically significant for the numbers tested. Topical haloperidol is therefore not likely to be a clinically useful agent in the treatment of patients with glaucoma.

Several factors may have contributed to the discrepancy between our results and those from animal work. In our patients haloperidol was instilled after corneal sensation had returned. Stinging was a feature of haloperidol instillation, and reflex hypersecretion may have washed the drug off the ocular surface. In a study of aqueous humour dynamics Chiou' instilled haloperidol at time 0 , contemporaneously with tonometry. These cats were anaesthetised with pentobarbital, and this may have prevented reflex tearing. Further, these eyes had indwelling cannulae at the time of eyedrop application, which may have artefactually increased drug penetration into the anterior chamber. Chiou's studies used the time taken to return to normal IOP after intravenous infusion of hypertonic saline as an index of rabbit aqueous humour secretion. ${ }^{36-8}$ It is possible that the mechanisms involved in the aqueous secretory response of the hyperosmolar experimental animal may differ from those maintaining physiological IOPs in humans. Finally, the question arises whether the laboratory animal and the human patient differ in their IOP pharmacology. Other workers have noted that the effect of timolol is less marked in experi- mental animals ${ }^{2910}$ than in humans. ${ }^{11}$ This may account for the differences between haloperidol and timolol in Chiou's studies. ${ }^{78}$

Chiou' showed that haloperidol acts by increasing aqueous humour outflow and reducing aqueous humour production. Although most effective glaucoma treatments still reduce normal IOPs by 25 $30 \%$, it is possible that dopamine receptor blockers may have a greater effect in patients with glaucoma or raised IOPs. These factors may explain the discrepancies between results in human volunteers and animals.

In conclusion we find that a study of the use of haloperidol in normal human volunteers does not support a role for haloperidol as an effective glaucoma treatment. Caution is required in extrapolating results from experimental animals to humans.

We thank the medical, paramedical, and nursing staff at the Western Ophthalmic Hospital for volunteering for this study. We thank Mr Redmond Smith for advice and encouragement.

\section{References}

1 Shields MB. A study guide for glaucoma. Baitimore: Williams and Wilkins, 1982: 415-6.

2 Neufeld AH. Experimental studies on the mechanism of action of timolol. Surv Ophthalmol 1979; 23: 363-70.

3 Liu HK, Chiou GCY. Continuous, simultaneous and instant display of aqueous humour dynamics with a microspherophotometer and a sensitive drop counter. Exp Eye Res 1981; 32: 583-92.

4 Wentworth WO, Brubaker RF. Aqueous humour dynamics in a series of patients with third neuron Horner's syndrome. Am J Ophthalmol 1981; 92: 407-15.

5 Wantanabe K, Chiou GCY. Action mechanism of timolol to lower the intraocular pressure in rabbits. Ophthalmic Res 1983; 15: $160-7$.

6 Chiou GCY, Chiou F. Dopaminergic involvement in intraocular pressure in the rabbit eye. Ophthalmic Res 1983; 15: 131-5.

7 Chiou GCY. Ocular hypotensive actions of haloperidol, a dopaminergic antagonist. Arch Ophthalmol 1984; 102: 143-5.

8 Chiou GCY. Treatment of ocular hypertension and glaucoma with dopamine antagonists. Ophthalmic Res 1984; 16: 129-34.

9 Macri FJ, Sevario SJ, Halel J. Timolol inhibition of isoproterenol action. 1. Effects on aqueous humour production and intraocular pressure. Gen Pharmacol 1980; 11: 207-11.

10 Neufeld AH, Bartels SP, Liu JHK. Laboratory and clinical studies on the mechanism of action of timolol. Surv Ophthalmol 1983; 28: 286-90.

11 Zimmerman TJ, Kaufmann HE. Timolol: a beta adrenergic blocking agent for the treatment of glaucoma. Arch Ophthalmol 1977; 95: 601-4.

Accepted for publication 17 October 1985. 